EvENTOS 


\title{
CÉREbro E O USO DE DROGAS NA INFÂNCIA E ADOLESCÊNCIA ${ }^{\star}$
}

\author{
Hugo Leonardo Rodrigues Soares $\star \star$ \\ Hérica Cristina Batista Gonçalves $\star \star \star$ \\ Jairo Werner Junior ${ }^{\star \star \star \star}$
}

Palavras-chave: plasticidade neural; drogas; adolescência.

Introdução: As primeiras experiências com drogas ocorrem freqüentemente na adolescência. Nessa fase, geralmente ocorrem grandes mudanças biopsicosociais. Esses aspectos psicológicos, socioculturais e neurológicos têm sido amplamente pesquisados de maneira a entender a associação entre infância/ adolescência e a maior susceptibilidade em relação à experimentação e uso de drogas. Pesquisas baseadas em exames de ressonância magnética funcional, mostram que novas conexões cerebrais são formadas intensamente no cérebro adolescente, comparando-se apenas ao período pós-natal imediato. As maiores mudanças ocorrem no córtex pré-frontal, região que coordena o pensamento "executivo", em outras palavras, a habilidade de usar a lógica, tomar decisões e avaliar possíveis riscos. Esta estruturação cerebral ajuda a explicar o porquê do comportamento peculiar do adolescente. Há uma complexa rede de neurônios que é ativada quando fazemos atividades que causam prazer, essa busca constante por estímulos prazerosos, está associada a um "sistema cerebral de recompensa". Todos os comportamentos que são reforçados por uma recompensa tendem a ser repetidos e aprendidos. Biologicamente, esse sistema visa garantir a sobrevivência, através da motivação de comportamentos como comer, beber e reproduzir-se. O uso de álcool e outras drogas de abuso também estimulam esse sistema, muitas vezes gerando um prazer muito mais intenso do que as funções naturais. Por provocar inicialmente euforia e bem-estar, os adictos têm uma falsa sensação de efeito benéfico, porém, o uso repetido e frequente acabam conduzindo a um ciclo vicioso, que afeta o cérebro e outros órgãos. A ação de ínfimas quantidades de droga que chegam ao cérebro alteram, e muito, o comportamento, ao atuarem nos mecanismos normais da neurotransmissão. Faz-se necessário entender melhor os mecanismos psicológicos individuais e sociais embasam a drogadição. Afinal, todos

^ Trabalho apresentado na $29^{\text {a }}$ Semana Científica da Faculdade de Medicina da UFF, realizada em 30 de novembro e 1 de dezembro de 2006, no Hospital Universitário Antônio Pedro, Niterói, Rio de Janeiro.

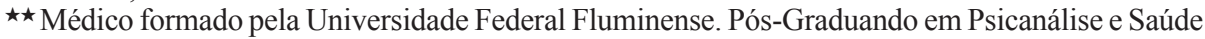
Mental pela UERJ. Ex-monitor das disciplinas de Neuropsiquiatria Infantil e Desenvolvimento Infantil. Especialista em Dependência Química pela UNIFESP/EPM. Pòs-Graduado (lato sensu) Políticas, Instituições e Saúde Mental e Vigilância Sanitária. Fiocruz/Ensp.

E-mail: hlsoares@brfree.com.br

$\star \star \star$ Psicóloga, residente em Saúde Mental do Instituto Municipal Philippe Pinel. E-mail: hericacris@yahoo.com.br

$\star \star \star \star$ Orientador e professor adjunto IV, responsável pela área de Psiquiatria da Infância e Adolescência da Faculdade de Medicina (Departamento Materno Infantil) do Centro de Ciências Médicas da UFF. Médico e Doutor em Saúde Mental -UNICAMP e Mestre em Educação - UFF. Endereço: Departamento Materno-Infantil - Faculdade de Medicina - Hospital Universitário Antônio Pedro (HUAP) - Rua Marquês do Paraná, 303, Centro, Niterói - RJ, CEP 24303-900.

E-mail: jairowerner@globo.com

Fractal: Revista de Psicologia, v. 22 - n. 3, p. 639-640, Set./Dez. 2010 
possuem esses sistemas cerebrais, neurotransmissores e receptores, mas apenas alguns estão suceptíveis ao uso e abuso de drogas. Objetivos: Apresentar uma abordagem biopsicosocial do consumo de álcool e drogas na infância e adolescência explicando os mecanismos de atuação da droga no cérebro, especialmente nessa fase de intensa atividade neural que é a adolescência, sem deixar de valorizar a atenção redobrada dos pais e responsáveis aos adolescentes, devido ao fácil acesso ao álcool, cigarros e drogas. Metodologia: Levantamento bibliográfico da literatura. Resultados e Conclusões: Quanto mais cedo o início de uso de drogas, maior o risco de dependência, de transtornos mentais associados e de comportamento alterado em decorrência do uso de drogas. Isso ocorre devido à plasticidade neuronal, que quando estimulada, provoca um rearranjo sináptico. Há também a alteração na recaptação de neurotransmissores, especialmente a dopamina. Toda droga libera dopamina nas áreas mesocórtica e mesolímbica, que irá afetar o sistema Límbico. Tanto a adolescência como o uso de drogas, sozinhos, levam a diminuição do número de receptores dopaminérgicos no sistema de recompensa, quando juntos, aliados ainda ao estresse, provocam uma redução radical na capacidade de ativação do sistema. Essa conjunção, quando presente em grande parte da adolescência, irá se consolidar na idade adulta, resultando num número abaixo do normal de receptores de dopamina. O indívíduo inerente a essa condição torna-se especialmente propenso ao vício, com grandes chances de desenvolver problemas relacionados ao abuso de drogas. 